\title{
Pengembangan Sistem Informasi Ujian Sekolah Berbasis Intranet DI SMK Basyariyah Madiun
}

\author{
Sujarwo* \\ Dosen Fakultas MIPA Universitas Pesantren Tinggi Darul Ulum Jombang \\ *email : jarwo@mipa.unipdu.ac.id
}

\begin{abstract}
This study develops school management are now many who utilize information systems, such as the Academic Information Systems, Information Systems Officer and others. But the system is still manual examination conducted that the teachers should make printed matter and must be propagated so it takes a long time as well as substantial funds for the preparation of the manuscript matter and answer sheet. Students also have to write it manually using pens to answer such questions. The efficiency and effectiveness of the exam committee less can optimally process the student assessment test results. By implementing a needs analysis (requirement analysis) to determine the needs of the system, then the author can specify a matter of necessity in the course of this intarnet based school exams, by making a new form of learning systems by implementing an intranet-based school examination system, providing convenience to each teacher in the field of study melaksankan school exams to students, to look for effective learning solution is to create an intranet-based school examination system, to develop skills in information technology-based learning. Exam Application Design School The school will be applied in the intranet, where these applications can be accessed by all computers clien in one room, so that examinees can access the questions from the server to the model question multiple choice / multiple choice is random and student test carried out in komputer.sehingga lab can provide efficiency in various aspects, namely the efficiency of time and cost efficiency. Design of information systems intranet-based school exam this is by using the PHP programming language and MySQL database MySQL used a database that has a very high process capability and save memory, it is very supportive of the school information system web-based exam.
\end{abstract}

Keywords: Information Systems; php; MySql.

\begin{abstract}
ABSTRAK
Penelitian ini mengembangkan Manajemen sekolah saat ini sudah banyak yang memanfaatkan sistem informasi, seperti Sistem Informasi Akademik, Sistem Informasi Kepegawaian dan lain-lain. Namun sistem ujian yang dilaksanakan masih manual yaitu guru harus membuat soal yang dicetak dan harus diperbanyak sehingga memerlukan waktu yang lama serta dana yang cukup besar untuk pembuatan naskah soal maupun lembar jawaban. Siswa pun harus menulis secara manual menggunakan bolpoint untuk menjawab soal-soal tersebut. Efisiensi dan efektifitas panitia ujian kurang bisa maksimal dalam proses penilaian hasil ujian siswa. Dengan menerapkan analisis kebutuhan (requirement analysis) untuk mengetahui kebutuhan sistem, maka penulis dapat menspesifikasikan masalah kebutuhan dalam proses jalannya ujian sekolah berbasis intarnet ini, dengan menjadikan bentuk sistem belajar yang baru yaitu dengan menerapkan sistem ujian sekolah berbasis intranet, memberikan kemudahan kepada masing-masing guru bidang study dalam melaksankan ujian sekolah pada peserta didik, untuk mencari solusi pembelajaran yang efektif yaitu dengan membuat sistem ujian sekolah berbasis intranet, mengembangkan kemampuan dalam pembelajaran berbasis teknologi informasi. Rancang Bangun Aplikasi Ujian sekolah Sekolah ini akan diterapkan di jaringan intranet, dimana aplikasi ini dapat diakses oleh semua komputer clien dalam satu ruangan, sehingga peserta ujian dapat mengakses soal dari server dengan model soal multiple choice/pilihan ganda yang random dan tempat ujian siswa dilaksanakan di laboratorium komputer.sehingga dapat memberikan efisiensi di berbagai aspek, yaitu efisiensi waktu dan efisiensi biaya. Perancangan sistem informasi ujian sekolah berbasis intranet ini yaitu dengan menggunakan bahasa pemrograman PHP MySQL dan database MySQL yang digunakan merupakan database yang memiliki kemampuan proses sangat tinggi dan menghemat memori, hal ini sangat mendukung sistem informasi ujian sekolah berbasis web.
\end{abstract}

Kata kunci : Sistem Informasi; php; MySql 


\section{Pendahuluan}

Perkembangan teknologi komputer saat ini sangat berpengaruh terhadap perkembangan berbagai bidang kehidupan. Manajemen sekolah saat ini sudah banyak yang memanfaatkan sistem informasi, seperti Sistem Informasi Akademik, Sistem Informasi Kepegawaian dan lainlain. Namun sistem ujian yang dilaksanakan masih manual yaitu guru harus membuat soal yang dicetak dan harus diperbanyak sehingga memerlukan waktu yang lama serta dana yang cukup besar untuk pembuatan naskah soal maupun lembar jawaban. Siswa pun harus menulis secara manual menggunakan bolpoint untuk menjawab soal-soal tersebut. Efisiensi dan efektifitas panitia ujian kurang bisa maksimal dalam proses penilaian hasil ujian siswa.

Berdasarkan hal tersebut, maka penulis tertarik untuk membuat suatu sistem komputerisasi ujian sekolah sekolah. Dengan adanya sistem ini diharapkan dapat mempermudah dan membantu pihak sekolah dalam mengadakan ujian sekolah sekolah dimana dalam penyajian soal akan terkemas secara praktis dan penjawaban soal ujian akan dinilai secara otomatis. Serta meminimalis dana untuk alokasi ujian sekolah, Maka penulis akan membahas suatu sistem ujian sekolah sekolah berbasis intranet pada SMK Basyariyah Madiun.

Pada proyek Rancang Bangun sistem informasi ujian sekolah sekolah berbasis intranet di SMK Basyariyah Madiun, kami menggunakan bahasa pemrograman PHP dan database Mysql yang mengacu pada Aplikasi berbasis web.

Rancang Bangun Aplikasi Ujian sekolah Sekolah ini akan diterapkan di jaringan intranet, dimana aplikasi ini dapat diakses oleh semua komputer clien dalam satu ruangan, sehingga peserta ujian dapat mengakses soal dari server dengan model soal multiple choice/pilihan ganda yang random dan tempat ujian siswa dilaksanakan di laboratorium komputer. Dari hasil sistem tersebut maka efektifitas dan efisiensi ujian sekolah akan diharapkan dapat dirasakan pihak sekolah maupun siswa.

Tujuan dari penulisan Penelitian ini adalah untuk membangun sistem ujian sekolah sekolah berbasis intranet yang dapat diakses oleh peserta ujian melalui jaringan (LAN) Local Area Network. ,sehingga menambah efektifitas dan efisiensi untuk proses penilaian siswa serta mengurangi anggaran ujian. Meningkatkan pengetahuan teknologi informasi kepada siswa ataupun guru dalam proses belajar mengajar. Membangun sistem informasi ujian sekolah berbasis intranet dengan menggunakan bahasa pemrograman PHP database MySQL. Meningkatkan efisiensi dan produktivitas pengelolaan lembaga pembelajaran. Meningkatkan kinerja dan kualitas pembelajaran melalui dukungan multimedia.

\section{Kerangka Teori}

sistem ulangan yang memakai jaringan privat (privat network), yang menggunakan protokol-protokol internet (TCI/ IP), alamat IP, dan protokolprotokol lainnya, baik klien atau pun server. Yang bertujuan untuk membagi suatu informasi atau pun data antar Intranet, dapat saling berkomunikasi satu dengan yang lainnya melalui sambungan kabel yang memberikan tulang punggung dalam membagi suatu informasi atau pun data.

Sistem informasi ujian sekolah berbasis intranet ini dalam proses penilaiannya berdasarkan Surat Keputusan Kepala Sekolah SMK Basyariyah Madiun proses penilaiannya hanya sampai pada proses pencetakan saja yang di berikan kepada masing - masing guru bidang studi dalam bentuk print out atau cetak. 
Menurut Robert A. Leitch ; Sistem Informasi adalah suatu Sistem di dalam suatu organisasi yang mempertemukan kebutuhan pengolahan transaksi harian, mendukung operasi, bersifat manajerial dan kegiatan strategi dari suatu organisasi dan menyediakan pihak luar tertentu dengan laporan-laporan yang diperlukan. (http://willis.comze.com/pengertian_infor masi.html, 09-03-2010)

Sistem adalah kumpulan elemenelemen yang saling berinteraksi satu sama lain untuk mencapai tujuan yang telah ditetapkan. Sebuah sistem terdiri bagianbagian yang saling berkaitan yang beroperasi bersama untuk mencapai beberapa sasaran atau maksud, tujuan dan sasaran yang sama. (http://willis.comze.com/pengertian_infor masi.html, 09-03-2010)

\subsection{Pemrograman PHP}

PHP merupakan kependekan dari kata Hypertext Preprocessor. PHP tergolong sebagai perangkat lunak yang open source yang diatur dalam aturan general licences. Pemrograman PHP sangat cocok di kembangkan dalam lingkungan web, karena PHP bisa diletakkan pada script HTML atau sebalikknya. PHP dikhususkan untuk pembangunan web dinamis, maksudnya, PHP mampu menghasilkan website yang secara terus menerus hasilnya bisa berubah-ubah sesuai dengan pola yang diberikan. Hal tersebuat tergantung pada clien browser-nya. (bisa menggunakan browser Opera,Internet Explore, Mozilla, dan lain-lain) HP tergolong juga sebagai bahasa pemrograman yang berbasis server (server side scripting) ( Dodit Suprianto, 2008 hal: 17).

PHP ditulis dengan dasar bahasa C, PHP juga merupakan Open-Source Technology yang dapat disebarkan dan dikembangkan dengan lisensi secara gratis (General Public Licences). PHP sendiri digunakan oleh lebih dari 20 juta dumain (menurut survey pada http://www.php.net/usage.php 12-032010).

PHP merupakan bahasa pemrograman skrip yang diletakkan dalam server yang biasa digunakan untuk membuat aplikasi web yang bersifat dinamis. PHP mendukung berbagai database. Termasuk yang didukungnya adalah MySQL. Dengan demikian, database yang anda muat dengan $M y S Q L$ dapat diakses oleh PHP dan memungkinkan untuk menampilakn isinya atau bahkan memanipulasi datanya melalui halaman Web (Abdul Kadir, 2008 hal: 358).

Adapun kelebihan-kelebihan dari PHP adalah:

a. PHP mudah dibuat dan kecepatannya sangat tinggi

b. HP dapat berjalan dalam web server yang berada dan dalam sistem operasi yang berbeda pula.PHP dapat berjalan di sistem operasi UNIX, Windows98, Windows NT dan Macinthosh.

c. PHP diterbitkan secara gratis

d. PHP juga dapat berjalan pada web server Microsoft Personal Web server, Apache, IIS, Xitami dan sebagainya.

e. PHP adalah bahasa yang embedded (bisa di temple atau diletakkan dalam tag HTML). ( Sutarman, 2007 hal: 95)

\subsection{Database MySQL}

Database adalah kumpulan data yang disimpan ke dalam sebuah file atau beberapa file. Dalam sistem informasi komputer database adalah sebuah kumpulan data yang tersusun secara sistematis sehingga akan memudahkan pengguna untuk mengakses dan mengatur sehingga akan menghasilkan sebuah informasi yang efektif dan efisien. (Andi, 2005 hal: 45) 
Secara umum database berarti koleksi data yang saling terkait. Secara prtaktis, basis data dapat di anggap sebagai suatu penyusunan data yang terstruktur yang di simpan dalam media pengingat (hard disk) yang tujuannya adalah agar data tersebut dapat diakses dengan mudah dan cepat.

MySQL adalah sebuah program database server yang mampu menerima dan mengirimkan datanya dengan sangat cepat, multi user serta menggunakan perintah standar SQL (Structured Query Language).

MySQL merupakan software yang tergolong DBMS (Database Management sistem) yang bersifat open source. Open source menyatakan bahwa software ini dilengkapi dengan Source Code (kode yang dipakai untuk membuat $M y S Q L$, selain tentu saja bentuk executable-nya atau kode yang dapat dijalankan secara langsung dalam sistem operasi.

MYSQL awalnya bibuat oleh perusahaan konsultan bernama TeX yang berlokasi di swedia. Saat ini pengembangan $M y S Q L$ berada di bawah naungan perusahaan $M y S Q L A B$. Selain itu $M y S Q L$ juga memilki beberapa kelebihan dibanding database lain, diantaranya adalah:

a. Multiplatform

MySQL tersedia pada beberapa platform (Windows, Linux, Unix dan lain-lain).

b. Handal, Cepat, Mudah di gunakan

$M y S Q L$ tergolong sebagai database server (server yang melayani permintaan terhadap database).

c. Jaminan keamanan akses

MySQ1 mendukung pengamanan database dengan berbagai kriteria pengaksesan.

d. Dukungan SQL

Seperti tersirat dalam namanya, MySQLmendukung perintah SQL (Structured Query Language).
Sebagaimana diketahui, SQLmerupakan standar dalam pengaksesan database rasional. Pengetahuan akan SQL akan memudahkan siapa pun untuk menggunakan $M y S Q L$

(Abdul Kadir, 2008 hal: 2-3)

\subsection{Data flow diagram (DFD)}

Pada tahun 1967, Martin dan Estin memperkenalkan suatu Algoritma program dengan menggunakan simbol lingkungan dan panah untuk simbol yang sama. G.E. Yourdan dan Constantine juga menggunakan simbol ini untuk membuat model-model sistem matematika. Ada beberap simbol yang digunakan pada DFD untuk maksud mewakili sebagai berikut :

a. External Entity ( kesatuan luar)

Setiap sistem pasti mempunyai batasan sistem (Boondary) yang memisahkan satu sistem dengan lingkungan luarnya, sistem akan menerima input dan menghasilkan output kepada lingkungan luarnya. Kesatuan luar (external entity) merupakan kesatuan dilingkungan laurnya yang akan memberikan input atau menerima output dari sistem.

b. Data Flow ( Arus Data )

Data flow di DFD simbolnya suatu panah. Data flow ini menunjukkan arus dari data yang dapat berupa masukan untuk sistem atau hasil sistem.

c. Process (proses)

Suatu proses merupakan kegiatan atau kerja yang dilakukan oleh sebuah mesin atau komputer dari hasil data flow diagram yang keluar dari proses. Dalam penulisan proses harus jelas identifikasi proses menunjukkan nomor acuan dan nama proses yang menunjukkan apa yang dikerjakan.

d. Data Store (penyimpan data) 
Penyimpanan data dapat berupa:

1) Suatu file data base di sistem computer

2) Suatu arsip atau catatan manual

3) Suatu kotak tempat data di meja seseorang

4) Suatu tabel acuan manual

5) Suatu agenda atau buku

Simpanan data pada DFD dapat disimpan dengan sepasang garis horisontal paralel yang tertutup disalah satu ujungnya atau dua garis paralel. (http://willis.comze.com/artikel_Data

Flow Diagram.html,15-03-2010).

\subsection{ERD (Entity relation diagram)}

Definisi menurut Ir. Eko Nugroho, MS, Pengolah Instalasi Komputer, diagram hubungan antara entity merupakan suatu dokumentasi data perusahaan dengan mengidentifikasi entity data dan memperlihatkan hubungan yang ada di antara entity tersebut.

(http://yanazmi.blogspot.com/2009/04/pen gertian-Entity relation diagram.html, 1503-2010)

a. Entity

Entity merupakan obyek yang eksis dan dapat dibedakan dengan obyek lain. Didokumentasikan sebagai suatu bentuk segi empat. Entity dapat berupa orang, tempat, kejadian atau konsep tentang data yang tercatat.

b. Relasi

Didokumentasikan dalam bentuk kotak yang berbentuk wajik dengan garis yang dihubungkan dengan tipe-tipe entitas terkait,

c. Atribut

Atribut adalah karakteristik dari entity atau relationship yang menyediakan penjelasan detail tentang entity/relationship tersebut.

Proses normalisasi merupakan proses pengelompokan data elemen menjadi tabel-tabel yang menunjukkan entity dan relasinya. Pada proses normalisasi selalu diuji pada kondisi. Apakah ada kesulitan pada saat menambah ( insert), menghapus ( delete), mengubah
( update), membaca ( retrieve ) pada suatu database.

(http://willis.comze.com/ Konsep Dan

Perancangan Database.html, 15-03-2010)

Kunci dibagi menjadi :

a. Candidate Key ( Kunci Kandidat/Kunci calon )

Kunci kandidat adalah satu atribut atau satu set minimal atribut yang mengidentifikasikan secara unik kejadian spesifikasi dan entity. Jika satu kunci kandidat berisi lebih dari satu atribut maka biasanya disebut sebagai komposite key ( kunci campuran/gabungan ).

b. Primary Key ( Kunci Primer )

Primary key adalah satu atribut atau satu set minimal atribut yang tak hanya mengidentifikasi secara unik satu spesifik tetapi juga dapat mewakili setiap kejadian dari suatu entity.

c. Foreign Key ( Kunci Tamu )

Adalah satu set atribut melengkapi satu relasi yang menunjuk ke induknya. Kunci tamu ditempatkan pada entity anak dan yang sama dengan primary key direlasikan. Hubungan entity induk dan anak adalah hubungan satu lawan banyak.

Dalam normalisasi dikenal adanya ketergantungan fungsi (Functional Dependency) yang diilustrasikan sebagai berikut : "diberikan sebuah relasi $\mathrm{r}$, atribut $\mathrm{Y}$ dan $\mathrm{R}$ adalah bergantung fungsi pada atribut $\mathrm{X}$ dan $\mathrm{R}$ jika dan hanya jika setiap nilai $X$ dan $R$ punya hubungan dengan tempat satu nilai $\mathrm{Y}$ dan $\mathrm{R}$ (dalam setiap satu waktu).

Normalisasi ada tiga macam bentuk yaitu :

\section{a. Bentuk Tidak normal unnormalized)}

Bentuk ini merupakan data yang akan direkam, tidak ada keharusan mengikuti form tertentu, data dikumpulkan apa 
adanya sesuai dengan kedatangannya.

b. Bentuk Normalisasi Pertama ( 1NF : First Normal Form )

Bentuk ini mengharuskan penghilangan atribut atau kelompok atribut yang berulang dari sebuah relasi.

c. Bentuk Normal Kedua ( $2 \mathrm{NF}$ : Second Normal Form )

Rancangan database dalam bentuk 2NF bila rancangan sudah ada dalam bentuk normal pertama dan semua atribut non kunci bergantung pada kunci parsial.

d. Bentuk Normal Ketiga ( $3 \mathrm{NF}$ : Third Normal Form )

Ciri dari bentuk ini adalah semua atribut bukan primer tidak mempunyai hubungan transitif, dengan kata lain setiap atribut bukan kunci harus bergantung hanya pada primary key secara menyeluruh dengan syarat relasi haruslah dalam bentuk normal kedua. ( http://willis.comze.com/ Konsep Dan Perancangan Database.html,15-03-2010)

\section{Metodologi}

\subsection{Bahan Penelitian}

Adapun teknik pengumpulan data yang digunakan yaitu:

a.Studi Pustaka

Yaitu mencari referensi dengan membaca buku-buku yang berhubungan dengan sistem ujian sekolah berbasis intranet, pemrograman PHP database MySQL, baik dari pustaka maupun dari referensi internet.

b.Metode Interview

Yaitu suatu teknik yang dilakukan dengan mengadakan dan mengajukan beberapa pertanyaan secara langsung kepada kepala sekolah dan guru SMK Basyariyah Madiun untuk memperjelas masalah yang diangkat yaitu perancangan dan penerapan sistem informasi ujian sekolah berbasis intranet.

c.Metode Dokomentasi

Yaitu dengan cara mengumpulkan dan menyusun informasi yang bersumber dari teori-teori literature, materi perkuliahan dan data hasil pengamatan yang pernah dilakukan berkaitan dengan judul yang telah diambil oleh penulis di SMK Basyariyah Madiun.

\subsection{Alat penelitian.}

Bahan penelitian yang berkaitan dengan kebutuhan umum mengetahui spesifikasi kebutuhan untuk sistem. Spesifikasi kebutuhan umum melibatkan perangkat keras, dan perangkat lunak.

a. Perangkat Keras

Perangkat keras merupakan salah satu hal yang harus diperhatikan, karena tanpa perangkat keras yang memenuhi syarat, aplikasi yang akan dibangun tidak akan bisa berjalan dengan baik. Berikut spesifikasi perangkat keras sesuai dengan asset yang tersedia :

$\begin{array}{ll}\text { Processor } & : \text { Dual Core } \\ \text { Memory } & : 128 \mathrm{Mb} \\ \text { Harddisk } & : 320 \mathrm{~GB}\end{array}$

b. Perangkat Lunak

Kebutuhan perangkat lunak merupakan faktor-faktor yang dibutuhkan untuk menunjang pembuatan aplikasi perangkat lunak itu sendiri, diantaranya adalah sebagai berikut :

Sistem Operasi :Microsoft Windows 7

Database : MySQL 5.0.67

Aplikasi Builder : PhP Designer 6.5.2

Web Server : Apache2 dan PHP 5.2.6

Web Browser : Mozilla Firefox v.3.0.6 dan IE 7 serta dilengkapi dengan flash plugin dan javascript enable.

\section{Pembahasan}




\subsection{Perancangan Sistem}

$\begin{array}{lcr}\text { Dengan } & \text { menerapkan } \\ \text { analisis kebutuhan } & \begin{array}{c}\text { (requirement } \\ \text { analysis) } \\ \text { kebutuhan }\end{array} \text { sistem } & \text { mengetahui }\end{array}$

kebutuhan sistem, maka penulis dapat menspesifikasikan masalah kebutuhan dalam proses jalannya ujian sekolah berbasis intarnet ini, dengan menjadikan bentuk sistem belajar yang baru yaitu dengan menerapkan sistem ujian sekolah berbasis intranet, memberikan kemudahan kepada masing-masing guru bidang study dalam melaksankan ujian sekolah pada peserta didik, untuk mencari solusi pembelajaran yang efektif yaitu dengan membuat sistem ujian sekolah berbasis intranet, mengembangkan kemampuan dalam pembelajaran berbasis teknologi informasi.

Langkah yang dilakukan kemudian dalam menganalisis kebutuhan adalah use case, dimana fungsional use case ini adalah memberikan suatu gambaran mengenai interface yang nanti akan dijalankan oleh administrator serta user.

\subsection{Desain Umum Sistem informasi} ujian sekolah berbasis intranet

Struktur sistem informasi langan harian berbasis intranet dapat dilihat pada gambc $\begin{array}{lll}\text { 'Web } & \text { t. }\end{array}$

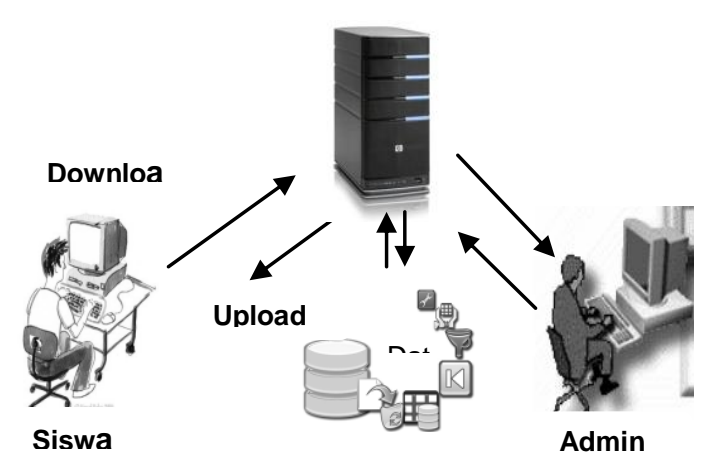

Gambar 1 Desain Umum ulangan berbasis intarnet.
Seorang siswa mengisi data melalui pc yang ada pada sistem informasi ujian sekolah berbasis intarnet. Inputan siswa berbasis intarnet ini mengirim informasi ke antarmuka admin melalui protokolprotokol internet (TCI/ IP). Dan seluruh data pada aktivitas tersebut disimpan pada sistem database MySQL.

\subsection{DFD}

Dari hasil analisis sebagai tahap awal perancangan program setelah dibuat use cese sebagai interface yang nanti akan dijalankan, lebih detailnya bisa dijabarkan atau digambarkan melalui Diagram Aliran Data (Data Flow Diagram/DFD) tersebut tentang alur perpindahan dan proses yang melibatkan data-data yang dibutuhkan oleh sistem, dari mana asal data dan kemana tujuan data yang keluar dari sistem, dimana data disimpan, proses apa yang menghasilkan data tersebut dan interaksi antara data yang tersimpan dan proses yang dikenakan pada data tersebut.

1. Proses Input soal, proses ini dilakukan oleh admin, soal yang diinputkan adalah soalsoal siswa yang kemudian disimpan dalam database soal, file hasil dari proses ini akan didownload oleh siswa untuk melakukan proses ulangan.

Setelah semua data-data soal yang valid dan tersimpan dalam database soal maka siswa akan mengakses atau download materi untuk proses ulangan. Sehingga akan mendapatkan hasil atau jawaban dari ulangan tersebut. Selain itu admin juga dapat melihat jawaban hasil dari ulangan siswa. Proses nilai, proses ini dilakukan setelah mendapatkan jawaban dari hasil ulangan siswa. Dimana baik siswa, ataupun admin dapat mengakses nilai dari ulangan siswa, yang sudah tersimpan dalam tabel nilai atau database nilai.

\subsection{ERD}

Rancangan ini membahas struktur database yang akan dipakai sehubungan dengan rancangan ERD yang telah di buat. Dalam hal merancanng struktur database, 
harus di tentukan field serta panjang tiap field yang akan digunakan pada ERD sebelumnya dan selanjutnya harus menentukan field apa yang merupakan primary key. Struktur file database yang dibutuhkan Entytas Admin memberikan nilai, admin dapat memberikan ujian dan nilai ke banyak siswa, Entytas siswa mengirimkan jawaban, banyak siswa mengirimkan ke banyak jawaban, Entytas Entytas guru dan mata pelajaran, satu guru memiliki banyak mata pelajaran.

\subsection{Desain Basis Data}

Dari spesifikasi yang telah dikembangkan pada tahap analisis, sehingga penulis dapat menentukan dan menyusun data-data yang akan digunakan dan disimpan dalam database untuk mendukung sistem ujian sekolah ini. penulis dapat menentukan relasi antar data yaitu pengelompokkan data yang terdiri dari table-tabel berdasarkan fungsi masingmasing antaralain : Table Admin berelasi dengan Tabel Siswa, Tabel Nilai, Tabel Mata pelajaran, Tabel Jawaban, dan Tabel Guru.

\section{Kesimpulan}

Setalah melakukan seluruh tahapan pembangunan sistem ujian sekolah di SMK Basyariyah Madiun meliputi tahap perancangan, implementasi dan pembahasan, dapat diambil kesimpulan beberapa hal terkait dengan proses pada tahapan-tahapan tersebut. Rancang Bangun Aplikasi Ujian sekolah Sekolah ini akan diterapkan di jaringan intranet, dimana aplikasi ini dapat diakses oleh semua komputer clien dalam satu ruangan, sehingga peserta ujian dapat mengakses soal dari server dengan model soal multiple choice/pilihan ganda yang random dan tempat ujian siswa dilaksanakan di laboratorium komputer.sehingga dapat memberikan efisiensi di berbagai aspek, yaitu efisiensi waktu dan efisiensi biaya. Perancangan sistem informasi ujian sekolah berbasis intranet ini yaitu dengan menggunakan bahasa pemrograman PHP MySQL dan database MySQL yang digunakan merupakan database yang memiliki kemampuan proses sangat tinggi dan menghemat memori, hal ini sangat mendukung sistem informasi ujian sekolah berbasis web.

\section{Daftar Pustaka}

Kadir, Abdul, belajar database menggunakan MySQL, Andi Offset, Yogyakarta, 2008.

Suprianto, Dodit, Buku pintar pemrograman $P H P$, OASE MEDIA Bandung, 2008.

Sutarman, Membangun Aplikasi web dengan $P H P$ \& MySQL, Edisi Kedua, Graha Ilmu,Yogyakarta, 2007.

Andi, Membuat Aplikasi Database Karyawan Online Berbasis Web Dengan PHP Dan MySQL, Andi offset Yogyakarta, 2005.

Fatichah, Chastine, Analisa dan perancangan sistem, PIKTI-ITS Surabaya,2005.

http://www.php.net/usage.php 12-032010).

(http://willis.comze.com/artikel_Data Flow Diagram.html, 15-03-2010). (http://yanazmi.blogspot.com/2009/04/pen gertian-Entity relation diagram.html, 1503-2010) 